\title{
HIV/AIDS discourses in Kyrgyzstan's policy arena
}

\author{
Svetlana Ancker*, Martin McKee, Bernd Rechel \\ *corresponding author
}

Svetlana Ancker, $\mathrm{PhD}$

Faculty of Public Health and Policy, Department of Health Services Research and Policy, London School of Hygiene \& Tropical Medicine, 15-17 Tavistock Place, London WC1H9SH, United Kingdom

sveta_ancker@yahoo.com

Tel: 02079272700

Prof. Martin McKee, MD

Faculty of Public Health and Policy, Department of Health Services Research and Policy

London School of Hygiene \& Tropical Medicine, 15-17 Tavistock Place, London WC1H9SH, United Kingdom

martin.mckee@1shtm.ac.uk

Tel: 02079272229

Bernd Rechel, $\mathrm{PhD}$

European Observatory on Health Systems and Policies, Faculty of Public Health and Policy, Department of Health Services Research and Policy, London School of Hygiene \& Tropical Medicine, 15-17 Tavistock Place, London WC1H9SH, United Kingdom

bernd.rechel@1shtm.ac.uk

Tel: 02076127808

Key words: HIV/AIDS, Kyrgyzstan, policy, discourse

\section{Abstract}

This article explores the major discourses on HIV/AIDS in the policy arena in Kyrgyzstan, a former Soviet country in Central Asia that has experienced a rapid rise in HIV infections since the early 2000s. Based on an analysis of policy documents and 54 semi-structured indepth interviews with key stakeholders in the area of HIV/AIDS policies in Kyrgyzstan, we distinguish a number of key discourses, competing for legitimacy and authority. While some of these discourses have been used in other countries (such as those presenting HIV/AIDS as a biomedical, social or moral issue), others are more specific to Kyrgyzstan (such as a discourse presenting the country as a regional pioneer in HIV/AIDS prevention efforts). Our analysis shows how HIV/AIDS discourses in the policy arena overlap and complement each other and how stakeholders employ a number of tools and strategies to promote and secure their agendas and positions of power. Our findings help to better understand HIV/AIDS discourses in Kyrgyzstan and elsewhere. They highlight the importance of understanding which discourses are prevailing, who drives them and why, how they change over time, and how they can be framed to achieve policy objectives. 


\section{Introduction}

As in other countries of Central Asia, HIV infections in Kyrgyzstan have increased steeply since the early 2000s, driven to a large degree by injecting drug use and commercial sex work. Although Kyrgyzstan initially adopted some of the most progressive HIV/AIDS laws and policies among the post-Soviet countries, its response to the epidemic has become increasingly fragmented. In the planning and implementation of HIV/AIDS policies and programmes, the institutions of the Kyrgyz state work alongside many international and national actors, each with their own agenda and pattern of engagement. HIV/AIDS policy has thus become highly politicised and contested, as many stakeholders compete for power and limited resources.

Discourses can construct an issue in a way that either attracts or diverts the attention of decision-makers and funders (Lupton 1994, 29). They are especially important where representations of an issue are contested, as with policies on HIV/AIDS, where different interest groups compete for ways to frame the issue. Often, certain constructions prevail through their claims to objectivity, legitimacy and professional authority, while ideas that do not fit these dominant discourses are dismissed as irrelevant (Plummer 1988, Rhodes 1997, Fischer 2003). At the same time, discourses are in a state of flux, depending on power relations and ideologies (Lupton 1994). Tactically, discourses, as methods of communication, offer opportunities to gain influence, achieve one's goals, and strengthen the positions of those using them, while undermining those of their opponents (Lupton 1994, van der Vliet 1996, Lupton 2003, Baumgartner and Mahoney 2008). Over the years, HIV/AIDS has become the scene of various competing, overlapping and complementary discourses, through which meanings are established, challenged and legitimized and which have an impact on how the disease is defined, perceived and managed (Sontag 1978).

While HIV/AIDS discourses have been examined in many countries, comparatively little attention has so far been paid to discourses in some of the former Soviet countries, in particular those in Central Asia. This article explores HIV/AIDS discourses employed in the policy arena of Kyrgyzstan, a post-Soviet country in Central Asia facing a major public health challenge from this disease. It examines how HIV/AIDS has been portrayed and how and by whom these representations have been produced, challenged, legitimized and maintained over time. The case of Kyrgyzstan is of relevance to many other former Soviet countries, as it was often upheld as a pioneer in HIV/AIDS policies in the region. Our analysis shows important commonalities with other post-Soviet countries, but also significant differences.

\section{Methods}

The study employed a qualitative approach, using semi-structured interviews and an analysis of academic and grey literature and national policy documents. Based on their participation in various HIV/AIDS policy initiatives and working groups and committees, the main stakeholder groups (including state institutions, NGOs, international organizations and the media) were identified through an initial literature review and discussions with 13 key informants during a pilot field trip in June 2011. A total of 54 interviews were then conducted in October-November 2011. These covered 21 heads of government departments and programmes concerned with HIV/AIDS (including various ministries, public health and law enforcement agencies, parliament and the government office), 15 programme managers in international organizations, 11 heads of NGOs and community organizations and 7 journalists regularly reporting on HIV/AIDS in various forms in leading newspapers and news agencies. 
New informants were added through the snowballing technique to include a variety of cases until saturation was reached. Interviewees in Kyrgyzstan were chosen by purposive sampling based on their professional knowledge and experience, as well as their influence and involvement in HIV/AIDS policy-making in 2004-2011 (as keepers of institutional memory). While some respondents spoke in their current official capacity, thus providing "public accounts" of the HIV/AIDS issue (Green and Thorogood 2009), others also gave their personal opinion or provided information on their experience at previous employers. We viewed this as advantageous, since information on multiple allegiances allowed unique and in-depth insights into the ways that different stakeholders perceived and treated the issue of HIV/AIDS.

In accordance with the ethical approvals from the authors' institute and the Ministry of Health in Kyrgyzstan, all interviewees gave signed informed consent. The scope of the interviews was intentionally kept broad and focused on HIV/AIDS policy-making in Kyrgyzstan, while the timeframe was limited to the period since 2004, when the first large-scale funding became available from the Global Fund to Fight AIDS, TB and Malaria (henceforth, "the Global Fund"). As data collection progressed, questions were adapted to elicit more insightful and critical information on emerging themes. The interviews were part of a larger study of the development of HIV/AIDS policies in Kyrgyzstan, including the roles of key actors, agendasetting, decision-making, power and influence, motivation and interests, and framings and popular attitudes towards HIV/AIDS.

All interviews, apart from one in English, were conducted in Russian, an official language in Kyrgyzstan and the lead author's mother tongue. Fifty-two interviews were recorded by digital recording and two by note-taking. Once conducted, the interview files were transcribed in Russian and checked for accuracy and completeness.

The interviews were complemented by review of a wide range of documentary sources, including 39 national HIV/AIDS policy-related documents. These included key academic and grey literature, Kyrgyzstan's official HIV/AIDS policy documents, as well as reports by national NGOs and international and organisations. Policy-related documents on HIV/AIDS in Kyrgyzstan were scrutinised to assess why they were created, what stories they tell and how they frame HIV/AIDS.

Different search parameters (e.g. types of materials, timeframe) and strategies (e.g. academic databases, library catalogues) were employed for different bodies of literature. To identify academic papers, a list of key words was used, including "Kyrgyzstan," "Central Asia," "HIV/AIDS," "politics," "framing," "moral," "security," "media," and "social construction." The electronic databases EBSCO, PubMed and EMBASE were searched and references followed up. Grey literature was identified using the Google search engine and the websites of the major international and local organizations working in the area of HIV/AIDS in Kyrgyzstan. Additionally, other published materials, many not available electronically, were collected during trips to Kyrgyzstan, meetings with international experts outside Kyrgyzstan and at international HIV/AIDS conferences.

We applied discourse analysis to the policy documents and the interview transcripts (Grbich 1999, Liamputtong and Ezzy 2005, Osborne and Neale 2009), which included selection and triangulation of data sources, reading and critically assessing texts, coding them, revising research questions (when necessary), identifying key discourses and connections between them, conceptualizing preliminary messages and findings and checking the reliability and 
validity of the analysis. Transcripts and documents were classified and analysed for emerging themes and categories, such as, for example, descriptions of particular populations, behaviours, relationships and responsibilities, and the ways these were framed and used in relation to HIV/AIDS policies. During this process we paid special attention to the power, status, and position of speakers, the social context in which each text was produced, its intended audience and the ideologies it was carrying. We also took account of the particular socio-historic and cultural context, rather than treating discourses as accurate representations of a reality fixed across time and space (Silverman 1997, Osborne and Neale 2009). While some of the discourses described below emerged early on in our analysis, were visibly delineated, and similar to discourses described elsewhere, others, such as the human rights discourse, became clearer only after meticulous reading and re-reading of interview transcripts and other texts.

\section{Results}

Our analysis of the interviews and documents allowed us to identify the main discourses on HIV/AIDS in Kyrgyzstan. They included discourses presenting HIV/AIDS as a biomedical, moral or social issue, discourses emphasizing human rights or portraying HIV/AIDS as a security threat, and a discourse that portrayed Kyrgyzstan as a regional "pioneer" in HIV/AIDS policy-making. The media has served as an important channel for promoting and reinforcing many of these discourses, such as the ones on HIV/AIDS as a moral issue or as a security threat, depending on media outlets and journalists.

\section{Biomedical discourse}

The biomedical discourse has been one of the most influential discourses in Kyrgyzstan. It views HIV/AIDS predominantly as a biomedical problem and maintains that medical professionals are best placed to deal with the epidemic. State medical institutions are presented by many respondents not only as the ones with authority over HIV surveillance, testing, reporting and education, but also as providers of HIV/AIDS prevention, treatment, care and support services. This privileged position and the legitimacy of the medical community have been secured and sustained through adoption and implementation of HIV/AIDS-related legislation and policies. For example, the 2005 HIV/AIDS Law stipulates that medical interventions, such as HIV testing, can be performed only by accredited health institutions (Nasriev et al., 2010). Additionally, the "Rules for HIV diagnostic testing, medical record-keeping and surveillance of individuals with positive and suspected with the results of the HIV testing in the Kyrgyz Republic" explicitly state that medical professionals implement surveillance, among other objectives, to control PLWHA's physical and mental wellbeing (Nasriev et al., 2010). It was only in later years that HIV/AIDS also came to be seen as a social issue requiring multisectoral action (see later section below).

Health professionals' knowledge and expertise have also been recognised by various stakeholders during our interviews as crucial for the development, planning and implementation of state HIV/AIDS policies (e.g. the State HIV/AIDS Programme), as well as for epidemiological interventions. A representative of a state health agency noted:

"Yes, physicians have started it all. That's why medical professionals write all state programmes. Well, there have been participants from the Ministry of Education, the State Penitentiary Service, and the government was the leader of the group. But, for the most part, it's considered a medical problem." 
Health experts, as described by informants from government departments, served as enthusiastic "engines" and advocates, pushing initial HIV/AIDS efforts and heading new state agencies and NGOs working on HIV/AIDS. Many respondents from the state health system agreed that health professionals at various levels of the system have been and should play a leading role in advocating and positioning HIV/AIDS in the policy arena, as well as making sure proposed policies are adopted and implemented.

Furthermore, since non-experts tend to trust the professional authority of state health institutions, starting with the Ministry of Health as the country's premier health policy organ, the expert opinion of health professionals matters. For instance, the success of opioid substitution therapy (OST) in Kyrgyzstan has been credited in part to progressive drug addiction specialists (not just infectious disease specialists) in key positions, their involvement in harm reduction policies and programme development, and advocacy at the policy level. As an NGO representative explained:

"And in those countries where the harm reduction programmes were led by the infectionists of the AIDS centres, maybe they didn't entirely understand the whole gravity of the drug addiction situation".

To illustrate the importance of this involvement, respondents used the example of Russia, where harm reduction efforts have been encountering numerous barriers because narcologists themselves are against them.

Health experts' opinions and knowledge have also been used by different sectors, such as local NGOs and the international community, to draw attention to HIV/AIDS and advocate for additional measures. However, regardless of their skills and expertise, some of the health professionals working in the HIV/AIDS sector in Kyrgyzstan admitted that they are not always included or are even actively excluded from the process of discussion and adoption of key policies at the higher political levels.

\section{HIVIAIDS as a moral issue}

In Kyrgyzstan, misunderstanding of HIV/AIDS continues among the general public, viewed as an issue that only affects people who behave in morally questionable ways, leading to high levels of stigma and discrimination. According to many of our respondents, in particular from the NGO sector, but also according to some authors (Iriskulbekov and Balabaeva 2008), HIV/AIDS has been portrayed as being an issue mostly affecting people engaging in risky behaviours (such as injecting drug use or sex work). In fact, the majority of HIV prevention efforts have been concentrated on these population groups, thus making the threat of HIV infections seem distant and abstract for the general population. As described by one NGO leader, HIV/AIDS is still seen by some people as:

"... a problem of drug users, sex workers, men who have sex with men and prisoners. These are, sort of, the lowest segments of the population, which can be ignored or even removed and shot. i.e. there are even such opinions."

The blame is placed not on the infection itself, but on people living with HIV, which are seen as the "sources" and "transmitters" of the "dangerous" virus. One journalist admitted in an interview that, in her reporting, she referred to HIV/AIDS as a "dangerous" (opasnaya) or "deadly" (smertele"naya) disease, justifying this in the following way: 
"I am for not scaring the population that it"s dangerous or mortally dangerous, but I am for warning. If they are informed, they are warned, and if warned, then saved".

Respondents' underlying moral judgments and attitudes towards HIV/AIDS became apparent in the use of words such as "trouble" (beda) and "evil" (zlo). Such moralistic language, reinforcing social stigma and fears, can be found not only among the general public and in the media (Sataev, Kirichenko et al. 2007, Bashmakova, Mamyrov et al. 2009a), but also - to some extent - in health legislation, official reports, and presidential speeches (Bashmakova, Alieva et al. 2009b, Nasriev, Sangoniv et al. 2010, SSDC 2013). Article 30 of the Law "On Public Health Protection in the Kyrgyz Republic", for example, describes the medical and social benefits for people with "socially significant" diseases and diseases that are "particularly dangerous" for society, which include HIV/AIDS (Nasriev, Sangoniv et al. 2010). Attitudes and moral judgments of policy-makers and HIV/AIDS stakeholders directly affect how this issue is perceived and dealt with in the policy arena. Displaying prevailing social attitudes, senior policy-makers blamed individuals for making poor choices that lead to negative health outcomes, while questioning why these population groups should be assisted and funds directed towards prevention, treatment, and support services. Our respondents noted that it has been particularly helpful to have two members of parliament with medical backgrounds and political credibility, who have been proactive and supportive advocates for HIV/AIDS policies and programmes, both in the parliament and the country coordinating committee on HIV/AIDS.

\section{HIVIAIDS as a "social" issue}

In Kyrgyzstan, the understanding of the disease in the HIV/AIDS sector has evolved from a purely medical perspective to one that sees it as a broader, social issue that requires a multisectoral and socially coherent response. Behind this framing of HIV/AIDS as a "social" issue, are both its social causes and effects. HIV/AIDS has been understood and described as a "social disease" in many of our interviews, as well as in national reports (CAAP 2011), partly because of the number of social factors, such as poverty, low levels of education, gender inequality, weak social and health infrastructure, and social behaviours that increase the risk of transmission. As a representative of a state health agency explained:

"So, you see, prevention of such infections, it cannot be just around some medical efforts. No, there are also many social factors that affect the transmission of infections."

HIV/AIDS is also framed as a "social" disease because of its potential negative impact on the health and well-being of the wider population, and, ultimately, its potential effect on the country's social and economic development (Bashmakova, Gorkina et al. 2007, Sataev, Kirichenko et al. 2007, Iriskulbekov and Balabaeva 2008). As the leader of one of the harm reduction NGOs said about the social impact of HIV/AIDS:

"It's a social problem, because it affects everything - the state budget, and the country "s wellbeing, and birth rates, and so on, so on ... and treatment".

To reflect this change in view, the official title of the State HIV/AIDS Programme was changed to "State Programme on Prevention of the HIV/AIDS Epidemic and its SocioEconomic Consequences in the Kyrgyz Republic". This recognized that everyone in society, regardless of their social status, can be faced with the risk of HIV transmission, and many 
stakeholders argued that, for an already impoverished country, the costs associated with the HIV/AIDS epidemic could potentially pose a serious socioeconomic challenge.

\section{HIVIAIDS as a security threat}

Partly related to the previous discourse on HIV/AIDS as a "social" issue, the disease has been portrayed by some national documents and study respondents (including from government agencies and NGOs) as a threat to national security. This "securitization" of HIV/AIDS has been linked to several factors, one of which is fear about the country's demographic development. HIV/AIDS is seen as a threat to Kyrgyzstan's demographic future, since it negatively affects birth rates, morbidity and mortality. Since about $70 \%$ of people living with HIV/AIDS in Kyrgyzstan are in the age group 20-39 (CCC 2012), parallels have been drawn with the worst epidemics in sub-Saharan Africa, where many of the most productive population groups have been affected, with consequences for national security. A programme manager from an international NGO expressed his concerns over the viability of Kyrgyzstan's population surviving:

"We say that any interference with the genetic pool, i.e. population decline and so on, it's dangerous...If we speak of the titular nationality [Kyrgyz - author], it's 3.5 million people living here. This is a very small population on the global scale."

According to national documents, a decline in the country's population due to HIV/AIDS would make it economically and socially unstable and vulnerable to both internal and external political and security threats (Bashmakova, Mamyrov et al. 2009a, Bashmakova, Alieva et al. 2009b, SSDC 2013).

Fears for the country's security are especially relevant in Kyrgyzstan, given its situation in a volatile region, bordering China, Kazakhstan, Uzbekistan Tajikistan, exposed to both Russian and American geopolitical interests. Thus, it is unique in the region in having had both an American (until 2014) and a Russian military airbase. In addition, it has experienced several coups and revolutions, as well as ethnic unrest. In this context, HIV/AIDS could be perceived as yet another potentially destabilising development. Some informants in our study, in particular from the NGO sector, as well as some national authors (Sataev, Kirichenko et al. 2007), have used powerful metaphors to portray HIV/AIDS as a "conqueror", a "weapon of mass destruction", an "unprecedented epidemic" and a "global health crisis", implying the need for urgent political attention and the mobilization of additional resources. The literature review also revealed a number of statistics that have been used widely to demonstrate, and sometimes exaggerate, the threat emanating from HIV/AIDS, such as Kyrgyzstan being one of seven countries in the world with the fastest HIV growth rates, HIV prevalence in the country increasing 55-fold in the last 10 years, and an alleged shift to a generalized epidemic due to high levels of heterosexual transmission of HIV (CMCC 2007, CMCC 2010, CCC 2012, MOH 2012b).

HIV/AIDS has also been framed as a security threat in Kyrgyzstan by the law enforcement sector, because of its connection (through drug use) to drug trafficking, as the country is located on one of three major regional drug-trafficking routes from Afghanistan (Murzalieva, Kojokeev et al. 2007, CCC 2012, MOH 2012b). As was noted by some interviewees and in other sources (Bashmakova, Alieva et al. 2009b, SSDC 2013), the drug trade and trafficking are tightly intertwined with crime and corruption, and, in some cases, terrorism, which is seen 
as a direct threat to national security and social stability. A programme head in one of the drug control agencies argued:

"But the problem of Afghan drugs, I am sorry, is not an internal problem of Kyrgyzstan. In this regard, we are, you know, in such a trap."

Local stakeholders employ a powerful argument by drawing a direct link between national and international security: if donors do not invest in anti-drug trafficking and HIV prevention activities, they will have to face long-term consequences of expanding drug trafficking, and, as a result, growing HIV rates in their own countries.

\section{HIVIAIDS as a human rights issue}

The global human rights agenda has supported the development of a human rights discourse, which was introduced and promoted in Kyrgyzstan by the international community and local NGOs. It is, therefore, not surprising that, while most national reports and policy documents mention the importance of protecting human rights, during the interviews this discourse came out strongest in conversations with representatives of international agencies and local NGOs. The role of the international community in Kyrgyzstan was crucial when it came to setting up the legal and policy framework, especially in the areas of work with most-at-risk populations (MARPs), building capacity of local NGOs for advocacy, and funding HIV prevention programmes based on a human-rights approach. As Kyrgystan's State HIV/AIDS Programme for 2012-2016 (MOH 2012b) stated:

"Stigma and discrimination prevent from accessing prevention, care and support services; lead to concealing of HIV status and, as a result, further transmission to sexual partners."

In some cases, donors suggested including human rights issues in a prescriptive manner: for instance, the 2010 technical guidance for HIV/AIDS proposals to the Global Fund encouraged a rights-based approach to HIV programming and outlined specific activities, such as legal services to PLWHA and legal reforms, to be included in the grant application (Global Fund 2010).

Driven by NGOs and international agencies, there have been several revisions of legal and policy documents on HIV/AIDS throughout the 2000s to better protect the human rights of affected populations (Murzalieva, Kojokeev et al. 2007, Bashmakova, Mamyrov et al. 2009a) and adhere to international norms and regulations. For instance, Kyrgyzstan revoked laws prohibiting sex between men and voluntary adult sex work, and eased legislation on drug possession and use. By doing so, Kyrgyzstan not only claimed that it was fulfilling its obligations in the international arena, but also positioned itself as a democratic country that respects human rights and freedoms and denounces punitive and coercive practices. All key HIV/AIDS and drug-related legislation and policies, programmes and Global Fund funding applications claim to base their efforts on international legal principles protecting human rights.

Despite these endeavours, the HIV/AIDS community is concerned about the interpretation of some legal clauses that are still ambiguous (Godinho, Renton et al. 2005) and stigma and discrimination towards at-risk groups and PLWHA continue. A head of a local NGO stressed 
the need for fundamental changes to law enforcement practices:

"We need to change some systemic approaches. I think that's where the problem is. We still cannot depart from harsh authoritarian methods or imprisonments. They [the law enforcement agencies] still cannot understand how they have to change their approaches of locking up and torturing to giving out syringes and so on".

\section{The image of Kyrgyzstan as a regional pioneer}

In both the literature (Bashmakova, Mamyrov et al. 2009a, UNODC/EHRN 2011) and during the interviews, Kyrgyzstan has often been referred to as a positive regional example and "pioneer". Key words used by interviewees to describe the country's image and achievements in the area of HIV/AIDS included: "first in the region", "leader", "innovative", "ahead of everyone", "progressive", "revolutionary", "advanced" and "exemplary". Indeed, Kyrgyzstan was one of the first post-Soviet countries to introduce antiretroviral treatment (in the late 1990s and early 2000s), set up a high-level multi-sectoral country coordinating mechanism, launch comprehensive healthcare reforms, develop and implement HIV prevention courses for the police forces, and initiate innovative HIV prevention programmes in prisons, such as OST and needle exchange. Kyrgyzstan's HIV/AIDS policy framework, based on multisectoral cooperation, has also been considered one of the most progressive in the region of Eastern Europe and Central Asia.

Its positive experiences and successes have been widely reported internationally and regionally and cited as a positive example at various regional and international conferences; delegations from other countries visited Kyrgyzstan to learn about some of its best practices (Bashmakova, Mamyrov et al. 2009a). Such commitment to the HIV/AIDS cause and rapid progress in implementation generated accolades from the international community, which was important for the national sense of pride of a small and newly independent state. As many respondents explained, such feedback in regional and international policy arenas inspired and energized national stakeholders to stay committed, work harder and advance closer to best international practices. As the State HIV/AIDS Programme (MOH 2012b) described:

"High levels of governmental commitment in fulfilling its obligations, adopted at the UN Assemblies, and effective implementation of prevention activities secured interest of international donors, and, thus, significant investment in this area."

Many in the sector thus also realized that a good reputation and international status brought higher funding allocations for HIV/AIDS, resulting in tangible material and non-material benefits. Consequently, the "pioneer" image was sustained and further promoted by HIV/AIDS stakeholders at national and international levels. However, some observers maintain that the image of a regional "pioneer," created through the hard work of many HIV/AIDS experts and professionals and maintained by interested stakeholders for many years, has been tarnished lately by the lack of progress and innovation, increasing HIV/AIDS rates, as well as by inefficiency and misappropriation of funds (Ancker, Rechel et al. 2013, Ancker and Rechel 2015). Furthermore, even though Kyrgyzstan may have been ahead of its neighbours, this does not mean that its efforts were sufficient. As one international expert in a donor agency explained: 
"I mean it's great to say we've scaled up methadone, but we are nowhere near the level of methadone enrolment, we are nowhere near the syringe distribution, we are nowhere near the targets you really need to hit to make a dent in the epidemic" 


\section{Discussion}

This article has explored the dominant HIV/AIDS discourses in Kyrgyzstan's policy arena and their main proponents. There have been notable changes in the importance of discourses over time, but some have also been remarkably resistant to change. Some HIV/AIDS discourses (such as the biomedical and moral discourses) have become weaker in the 2000s, at least as far as the "official" discourses were concerned, while others (such as the one on HIV/AIDS as a "social" issues or security threat) have gained more prominence. Major reasons for this shift in discourses include the new international HIV/AIDS agenda of the 2000s which helped to change the (official) discourse on the disease in particular in those countries that were dependent on donor funding, such as Kyrgyzstan. Furthermore, Kyrgyzstan also positioned itself as a regional success story, which helped to secure international funding for HIV/AIDS efforts and was thus associated with material and nonmaterial benefits.

As was the case in the West (Altman 1993, Donovan 1996, Treichler 1999) the biomedical discourse has been important in Kyrgyzstan from the onset of the HIV/AIDS epidemic, reflecting the authority of medical professionals and their technical knowledge and skills. The biomedical and health community controls not only the disease- naming and categorization process, but also the production and dissemination of scientific knowledge on HIV/AIDS, affecting public views about the disease, policy decisions and resource allocation (Lupton 1994, Rushing 1995, Waldby 1996). Yet the "traditional" authority of health professionals has been challenged by a new wave of HIV/AIDS experts. One international example is the mobilization of gay activists in the U.S., challenging the biomedical discourse and framing HIV/AIDS as a political and human rights issue (Gostin 2004). In Kyrgyzstan, as in other post-Soviet countries, the move from the purely biomedical framing of HIV/AIDS to a more inclusive social perspective in the 2000s was not only conducive to multi-sectoral coordination of HIV/AIDS efforts (a condition of Global Fund funding), but also facilitated the sharing of financial and management responsibilities between sectors. It helped to secure donor funding and changed the way the country shaped its response to HIV/AIDS. However, in the current context of declining Global Fund support, political incentives for multisectoral approaches might decline.

The discourse of Kyrgyzstan as a regional "pioneer", driven by both national and international stakeholders, shows how the country's earlier achievements and international recognition have become a source of pride and inspiration; however, the discourse has also been used strategically as an effective way of distinguishing itself from other post-Soviet countries and to attract foreign funding (Ancker and Rechel 2015). The contrast was perhaps most marked with Russia, which pursued restrictive drug policies, did not support harm reduction programmes and prohibited opioid substitution therapy (Pape 2014).

Yet, attitudes of blame towards at-risk populations and PLWHA and moral judgments about HIV/AIDS continue to be present at different levels of Kyrgyzstan's society, much as in many other post-Soviet countries (Rechel 2010). Organizations offering HIV/AIDS-related services and their client populations often face harassment and human rights violations, including by the police (while at the same time police cadres are being trained to be supportive of HIV/AIDS prevention efforts). Furthermore, although there have been claims of moving towards a "chronic" disease model, there is still a dissonance between 
stakeholders' declarations of being more progressive in their understanding of HIV/AIDS and using internationally accepted terminology, and the moralistic and intimidating language used by some in the interviews and, occasionally, in national policy and training materials. The discourse of HIV/AIDS as a moral issue has thus been largely resistant to change, at least as far as public attitudes are concerned.

One of the ways to bring attention to HIV/AIDS and mobilize resources has been to frame it as a security threat, as has been observed in many countries (DeWaal 2003c, Allen 2004, Elbe 2006). This concept emerged in the 1990s, when the U.S. government started framing HIV/AIDS in this way, and reached its peak in 2000, when the UN Security Council framed HIV/AIDS as an international security issue (Allen 2004). Following the events of 11 September 2001, there was a return to a more traditional security agenda (Pape 2014). However, in Kyrgyzstan, the framing of HIV/AIDS as a security threat still exists. This has to be seen in the context of the country's volatile situation in an unstable region, but is also related to developments in Russia, where, after years of inaction, President Putin, in 2006, expressed his concern about HIV/AIDS and its potential security implications for Russia. In the following years, HIV/AIDS remained on the country's security agenda (Pape 2014). In Kyrgyzstan, the securitization discourse, backed by national and international examples, is employed by stakeholders, in particular from NGOs, as an advocacy tool to warn the national leadership and the international community against the potential future costs arising from possible human and economic losses, the proliferation of transnational crime, instability and popular discontent. The deliberate securitization of HIV/AIDS may have captured some of the attention of national policy-makers, but seems to have had little impact on the perception of the issue by the general population, which, for the most part, continues to distance itself from the epidemic and perceives HIV/AIDS as a problem of the "other".

The human-rights approach is a cornerstone of universal access to HIV prevention, treatment and care (Operario, Betteridge et al. 2008, OSI/Equitas 2009). For the most part, civil society and international organizations can be credited with driving this discourse since the 1980s (Rofes 1998), and "exporting" it to the post-Soviet countries in the 1990s and 2000s (Pape 2014). They used a human-rights approach to promote public health measures and to fight against coercive and punitive governmental policies (Ouellette Kobasa 1991). On the other hand, violations of the rights of MARPs and PLWHA undermine HIV prevention efforts and inhibit the ability to access hard-to-reach populations and deliver necessary prevention, treatment and care services effectively (Operario, Betteridge et al. 2008). However, in Kyrgyzstan, as in many other post-Soviet countries (Rechel 2010), mainstreaming a humanrights approach into HIV/AIDS work has been challenging, due to various social, legal and political factors. One of the reasons is that the discourse was only used strategically, in official publications, grant proposals, donor reports or legislation, without it being embedded in how the issue was generally perceived, by both the public and by policy-makers. The situation is similar in many other post-Soviet countries (Rechel 2010). The protection of human rights more generally is still a major challenge in the country (as in many of its neighbouring countries) and this undermines how far the human rights of people affected by or at risk from HIV/AIDS can be protected and promoted.

\section{Conclusions}

This article has illustrated how some HIV/AIDS discourses in Kyrgyzstan's policy arena overlap, while others compete for legitimacy. For instance, the human rights discourse complements the framing of HIV/AIDS as a social disease, which promotes cooperation and inclusion, such as through collaboration, voluntary testing and the protection of the human 
rights of vulnerable and most-at-risk populations. In these two discourses, mainly put forward by NGOs and international organizations, HIV prevention and human rights go hand-in-hand and are indivisible. This logic challenges and competes with the concept of HIV/AIDS as a moral issue and as a security threat. While the former rationalizes curbing rights and freedoms of those perceived as "morally deficient" and "dangerous" for the health and development of society, the latter justifies "contain-and-control" measures, with compulsory testing and isolation of HIV-positive individuals, perpetuating stigma and discrimination of already marginalized population groups (Theodoulou 1996b). As was seen in the early days of HIV/AIDS in the U.S., such juxtaposition of "deviants" against "innocents" has important policy implications, as the former are seen as deserving to bear the burden of the disease, while the latter are seen as entitled to enjoy the benefits of social protection (Ostrow, Eller et al. 1988, Farmer 1999). This perception is still a particular challenge in Kyrgyzstan, and the situation is similar in many other post- Soviet countries (Rechel 2010).

While some of the discourses discussed in this article, such as the biomedical or moral discourse, have been characteristic of ways that the HIV/AIDS epidemic has been described in many parts of the world, the case of Kyrgyzstan confirms that most of these 'traditional' discourses are still very much alive, at least in post-Soviet countries. Other discourses, such as the image of Kyrgyzstan as a regional "pioneer", are more country-specific.

In all cases, discourses are used by stakeholders at times for achieving their particular goals. For example, the biomedical discourse, which secures the professional authority of the health sector, also becomes an advocacy tool in the hands of NGOs. At the same time, to attract political attention and secure donor funding, national stakeholders may employ arguments that are part of the security and "pioneer image" discourses. While the former discourse focuses on the potential threat of HIV/AIDS and uses a story of possible "decline", the latter encourages further investments to support and reward Kyrgyzstan as a regional "success" model, even though some observers maintain that progress in the response to the epidemic has waned (Ancker, Rechel et al. 2013).

By analyzing the discourse on HIV/AIDS, it is possible to glimpse how HIV/AIDS is understood, framed and communicated by a variety of stakeholders. Although our analysis was limited to a single country, it provides lessons for understanding HIV/AIDS policymaking in other low- and middle-income countries facing the HIV/AIDS epidemic, in particular the post-Soviet countries. Discourses, both in Kyrgyzstan and elsewhere, are political in nature and create narratives that suit particular interests and power positions of political and scientific elites and other stakeholders. HIV/AIDS discourses are more than semiotics and texts; through their claims to logic, neutrality and objectivity, they tend to conceal the political nature of policy-making and stakeholders' claims to power and resources. In order to better understand HIV/AIDS policies in low- and middle-income countries, it is crucial not only to understand how the issue is being framed and what discourses of the issue are prevailing, but also who drives them, and why, and how discourses are changing over time. While changes in official semantics might indicate progress, discourses of the past might linger on beneath the official surface and pose an insurmountable obstacle to addressing public health challenges. 


\section{References}

Allen, T. (2004). "Introduction: why don't HIV/AIDS policies work?" Journal of International Development 16(8): 1123-1127.

Altman, D. (1993). Expertise, Legitimacy and the Centrality of Community. AIDS: Facing the Second Decade. P. Aggleton, P. Davis and G. Hart. London, Falmer Press.

Ancker, S. and B. Rechel (2015). "Donors are not interested in reality': the interplay between international donors and local NGOs in Kyrgyzstan's HIV/AIDS sector." Central Asian Survey 34(4): 516-530.

Ancker, S. and B. Rechel (2015). "Policy responses to HIV/AIDS in Central Asia." Global Public Health 10(7): 817-833.

Ancker, S., B. Rechel, M. Mckee and N. Spicer (2013). "Kyrgyzstan: still a regional 'pioneer' in HIV/AIDS or living on its reputation?" Central Asian Survey 32(1).

Bashmakova, L., G. Alieva, A. Zelichenko, E. Zelichenko, K. Osmonalieva, B. Serocka and V. Tabaldieva (2009b). Legal Basis of Theory and Practice of Harm Reduction (Правовые основы теории и практики снижения вреда). Bishkek, Ministry of Internal Affairs/Academy of Ministry of Internal Affairs/Open Society Institute/Soros Foundation-Kyrgyzstan.

Bashmakova, L., V. Gorkina, C. Davletova, E. Kalieva and G. Chirikina (2007). HIV Infection Prevention. Manual for Pedagogical Professionals in Higher Education Institutions of the Kyrgyz Republic. Bishkek, Ministry of Education.

Bashmakova, L., M. Mamyrov, D. Sorombaeva and C. Imankulova (2009a). Overcoming Global Healthcare Problems: National Response to HIV Infection, Tuberculosis and Malaria in the Kyrgyz Republic. Bishkek, Ministry of Health/Macro International.

Baumgartner, F. and C. Mahoney (2008). "Forum Section: the two faces of framing." European Union Politics 9(3): 435-449.

CAAP (2011). Five Years of Work: Gained Experience and Next Steps. Almaty, Regional Project Management Group, Central Asia AIDS Project (CAAP).

CCC (2012). UNGASS Country Progress Report on HIV Infection Response - Kyrgyz Republic (January 2010- December 2011). Bishkek, Country Coordinating Committee (CCC) under the Government of the Kyrgyz Republic/Ministry of Health.

CMCC (2007). Funding proposal form (Kyrgyzstan) - Round 7. Geneva, The Global Fund to Fight AIDS, Malaria and Tuberculosis/Country Multi-sectoral Coordination Committee (CMCC) under the Government of the Kyrgyz Republic. 
CMCC (2010). UNGASS Country Progress Report - Kyrgyz Republic (January 2008December 2009). Bishkek, Country Multi-sectoral Coordination Committee (CMCC) under the Government of the Kyrgyz Republic/Ministry of Health.

DeWaal, A. (2003c). "How will HIV/AIDS transform African governance?" African Affairs 102(406): 1-23.

Donovan, M. (1996). The Politics of Deservedness: The Ryan White Act and the Social Constructions of People with AIDS. AIDS: the Politics and Policy of Disease. S. Theodoulou. Upper Saddle River, NJ, Prentice Hall.

Elbe, S. (2006). "Should HIV/AIDS be securitized? The ethical dilemmas of linking HIV/AIDS and security." International Studies Quarterly 50(1): 119-144.

Farmer, P. (1999). Infections and Inequalities: the Modern Plagues. Berkeley, CA, University of California Press.

Fischer, F. (2003). Reframing Public Policy. Discursive Politics and Deliberative Practices. Oxford, Oxford University Press.

Global Fund (2010). Technical Guidance Note for Global Fund HIV Proposals: Human Rights and Law. Geneva, The Global Fund to Fight HIV/AIDS, Tuberculosis and Malaria.

Godinho, J., A. Renton, V. Vinogradov, T. Novotny and J. Rivers (2005). Reversing the Tide: Priorities for HIV/AIDS Prevention in Central Asia. Washington, D.C., World Bank.

Gostin, L. (2004). The AIDS Pandemic: Complacency, Injustice, and Unfulfilled Expectations. Chapel Hill, The University of North Carolina Press.

Grbich, C. (1999). Qualitative Research in Health: an Introduction. London, Sage Publications.

Green, J. and N. Thorogood (2009). Qualitative Methods for Health Research. London, Sage Publications.

Iriskulbekov, E. and A. Balabaeva (2008). Legal Aspects of HIV/AIDS Coverage in Media. Bishkek, Legal Clinic "Adilet".

Liamputtong, P. and D. Ezzy (2005). Qualitative Research Methods. South Melbourne, Oxford University Press.

Lupton, D. (1994). Moral Threats and Dangerous Desires. AIDS in the News Media. London, Taylor \& Francis Books.

Lupton, D. (2003). Medicine as Culture: Illness, Disease and the Body in Western Societies. London, Sage Publications.

MOH (2012b). State Program on Prevention of HIV Epidemic and Its Social and Economic 
Consequences in the Kyrgyz Republic for 2012-2016 (Государственная программа по предупреждению эпидемии ВИЧ-инфекции и ее социально-экономических последствий в Кыргызской Республике на 2012-2016 годы). Bishkek, Ministry of Health $(\mathrm{MOH})$.

Murzalieva, G., K. Kojokeev, E. Manjieva, B. Akkazieva, A. Samiev, M. Jakab, G. Botoeva and M. Ablezova (2007). Tracking Global HIV/AIDS Initiatives and Their Impact in the Health Systems: the Experience of the Kyrgyz Republic. Draft Mapping Context Report. London, The Global HIV/AIDS Initiatives Network.

Nasriev, I., D. Sangoniv and Z. Kadyrov (2010). Collection of Normative Acts of the Central Asian Countries on HIV/AIDS (Сборник нормативных актов по вопросам ВИЧ/СПИДа стран Центральной Азии). Almaty, Regional Management Group on Control of AIDS in Central Asia.

Operario, D., G. Betteridge, L. N. Hsu, A. Ivanov, R. Jurgens, H. McLean, S. Milcher, M. Peleah, S. Sharp and D. Tarlton (2008). Living with HIV in Eastern Europe and CIS: The Human Cost of Social Exclusion. Bratislava, United Nations Development Programme.

Osborne, D. and J. Neale (2009). Discourse Analysis. Research Methods for Health and

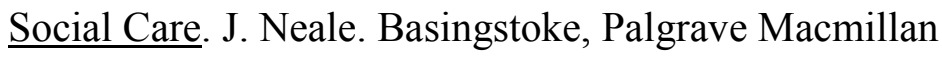

OSI/Equitas (2009). Health and Human Rights: a Resource Guide. New York, NY, Open Society Institute (OSI)/Equitas - International Centre for Human Rights Education

Ostrow, D., M. Eller and J. Joseph (1988). Epidemic Control Measures for AIDS: A Psychosocial and Historical Discussion of Policy Alternatives. AIDS: Principles, Practices and Politics. I. Corless and M. Pittman-Lindeman. Washington, D.C., Hemisphere Publishing Corporation.

Ouellette Kobasa, S. (1991). AIDS Volunteering: Links to Past and Future Prospects. $\underline{\mathrm{A}}$ Disease of Society: Cultural and Institutional Response to AIDS. D. Nelkin, D. Willis and S. Parris. Cambridge, Cambridge University Press.

Pape, U. (2014). The politics of HIV/AIDS in Russia. London, Routledge.

Plummer, K. (1988). Organizing AIDS. Social Aspects of Aids. P. Aggleton and H. Homans. London, Falmer Press.

Rechel, B. (2010). "HIV/AIDS in the countries of the former Soviet Union: societal and attitudinal challenges." Cent Eur J Public Health 18(2): 110-115.

Rhodes, T. (1997). Risk, Injecting Drug Use and the Myth of an Objective Social Science. Acting on AIDS: Sex, Drugs and Politics. J. Oppenheimer and H. Reckitt. London, 
Serpent's Tail.

Rofes, E. (1998). Dry Bones Breathe: Gay Men Creating Post-AIDS Identities and Cultures. New York, NY, Harrington Park Press.

Rushing, W. (1995). The AIDS Epidemic: Social Dimensions of an Infectious Disease. Boulder, CO, Westview Press.

Sataev, O., V. Kirichenko, R. Aitmatova, E. Besedin, E. Iriskulbekov, A. Bayalinov and Y. Puchkova (2007). How to Cover HIV/AIDS Issue in Media. Manual for Journalists. Bishkek, Country Coordinating Committee (CCC) under the Government of the Kyrgyz Republic.

Silverman, D. (1997). Qualitative Research: Theory, Method and Practice. London, Sage Publications.

Sontag, S. (1978). Illness as Metaphor. New York, NY, Farrar, Straus and Giroux.

SSDC (2013). Concept of the State Anti-Drug Strategy of the Kyrgyz Republic (draft). Bishkek, State Service on Drug Control (SSDC).

Theodoulou, S. (1996b). Responding to AIDS: Governmental Policy Responses. AIDS: the Politics and Policy of Disease. S. Theodoulou. London, Prentice Hall.

Theodoulou, S., G. Guevara and H. Minnassians (1996c). Myths and Illusions: the Media and AIDS Policy. AIDS: the Politics and Policy of Disease. S. Theodoulou. London, Prentice Hall.

Treichler, P. (1999). How to Have a Theory in Epidemic: Cultural Chronicles of AIDS. Durham, N.C., Duke University Press.

UNODC/EHRN (2011). Country Report on the Status Kyrgyz Republic's Implementation of Political Declaration and Action Plan on Improving International Collaboration to Develop Complex and Balanced Strategy to Counteract International Drug Problem (Страновой доклад о ходе выполнения Кыргызской Республикой Политической Декларации и Плана действий по налаживанию международного сотрудничества в целях выработки комплексной и сбалансированной стратегии борьбы с мировой проблемой наркотиков). Bishkek, United Nations Office on Drugs and Crime (UNODC)/The Eurasian Harm Reduction Network (EHRN).

van der Vliet, V. (1996). The Politics of AIDS. London, Bowerdean Publishing Company Ltd.

Waldby, C. (1996). AIDS and the Body Politic: Biomedical and Sexual Difference. London/New York, NY, Routledge.

Wellings, K. (1988). Perceptions of Risk- Media Treatment of AIDS. Social Aspects of Aids. 
P. Aggleton and H. Homans. London, Falmer Press. 